\title{
The Effects of Long-Term Ubiquinol Intake on Improving the Quality of Life of Community Residents
}

\section{Tetsu Kinoshita ${ }^{1,2}$, Koutatsu Maruyama ${ }^{3}$, Takeshi Tanigawa ${ }^{3}$}

${ }^{1}$ Department of Epidemiology and Preventive Medicine, Graduate School of Medicine, Ehime University, Toon, Ehime, Japan; ${ }^{2}$ Institute of Community Life Sciences Co., Ltd., Matsuyama, Ehime, Japan; ${ }^{3}$ Department of Public Health, Juntendo University Graduate School of Medicine, Bunkyo-ku, Tokyo, Japan

Corresponding Author: Tetsu Kinoshita, Shitsukawa, Toon-city, Ehime, 791-0295, Japan

Submission Date: October 29, 2015, Acceptance date: January 14, 2016: Publication date: January 16, 2016

\begin{abstract}
Background: Ubiquinol is widely used as an anti-aging supplement. In this study, we evaluated the effects of long-term ubiquinol intake on improving or maintaining the quality of life (QOL) of community residents.
\end{abstract}

Methods: 124 adult (aged 22-86) residents (36 male, 88 female) participated in this trial. Each consumed 100-120 mg of ubiquinol per day for 6 months $(n=22)$ or 12 months $(n=102)$. We measured serum ubiquinol levels and QOL scores by SF-36 at baseline and after ubiquinol intake.

Results: In female participants, the SF-36 scores of role physical (RP), vitality (VT), social functioning (SF), mental health $(\mathrm{MH})$, and mental component summary (MCS) increased significantly. On the other hand, significant score changes were not shown in male participants. After stratifying baseline serum ubiquinol levels by tertiles, we found a significant improvement of mental QOL scores in the low and middle ubiquinol level groups of female participants, but not in the highest tertile. 
Conclusions: This trial indicates that ubiquinol supplementation has effects on female participants' psychological QOL, especially for those whose baseline serum ubiquinol levels are in the low to middle range.

Trial Registration: UMIN Clinical Trial Registry UMIN000012612

Key Words: ubiquinol, coenzyme Q10, energy production, quality of life, clinical trial

\section{BACKGROUND}

Due to rapidly aging populations, many developed countries are currently facing numerous social problems related to their health insurance systems [1]. In Japan, the population aging rate is higher than those of all other advanced nations at approximately $25.0 \%$; this rate is further estimated to reach $40 \%$ by 2060 (Japanese Bureau of Statistics of the Ministry of Internal Affairs and Communications, 2013).

In Japanese society, the idea of a "healthy life-span" is just as important as one's overall life-span. As a result, the general public is required to practice disease prevention on their own in order to reduce their medical spending.

Coenzyme Q10 (CoQ10) is a vitamin-like substance present in nearly all human tissue [2]. CoQ10 has two main physiological roles: mitochondrial energy production [3] and antioxidant effects [4-5]. It is therefore widely consumed as an anti-aging supplement [6]. Many studies have reported that insufficient CoQ10 is associated with the development of congestive heart failure (CHF) [7-9], depression [10], chronic fatigue syndrome [11], diabetes [12], Parkinson's disease [13], and dementia [14].

To date, although no study has shown the effects of CoQ10 administration for the prevention of those diseases, several clinical studies have suggested that for patients undergoing medical treatment, CoQ10, or micronutrient supplements containing CoQ10, improve their quality of life (QOL) [15-17]. In recent decades, QOL has been regarded as an important health issue. The Constitution of the World Health Organization (WHO) (1946) states that good health is a state of complete physical, social, and mental well-being, and not merely the absence of disease or infirmity [18-19]. Therefore, studies to increase QOL are important and significant for both healthy and unhealthy individuals. In a previous study conducted with 11 healthy residents in a special elderly nursing home, CoQ10 supplementation was shown to have improved their QOL [20].

CoQ10 has two types of molecular structure: a reduced form (ubiquinol), and an oxidized 
form (ubiquinone). The one that has efficacious bioactivity in the body is ubiquinol [21]. When ubiquinone is ingested through daily food intake, it is converted into ubiquinol by NADPH-dependent ubiquinone reductase. Therefore, ubiquinol is likely a more effective dietary supplement than ubiquinone due to its direct bioactivity. Recent studies have reported that ubiquinol supplementation increases plasma CoQ10 levels for CHF patients [22] and decelerates the senescence in senescence-accelerated mice [23], while significant effects using ubiquinone have not been shown.

However, few clinical trials evaluating the effects of ubiquinol on maintaining or enhancing the health of non-diseased individuals have been conducted. One previous study using a test group of healthy elderly participants demonstrated the potential effect of ubiquinol on their mental health, but the sample group was small, and the study itself did not examine blood ubiquinol levels [20]. Further investigation on the effects of ubiquinol intake on healthy populations is therefore required.

In the present study, we conducted a clinical trial to evaluate the effects of long-term intake of ubiquinol on improving or maintaining the QOL of community residents in a "super-aging" region in Japan. This prospective trial has the potential to contribute to the health of elderly residents in general

\section{METHODS}

\section{Participants}

Ubiquinol Health Examination is an ongoing prospective intervention trial that started in November 2013. The participants are volunteers residing in Kamijima town, Ehime Prefecture. Kamijima is located approximately $700 \mathrm{~km}$ west of Tokyo in the Seto Inland Sea. Kamijima is a "super-aging" region with a population aging rate of $37.7 \%$ according to the 2010 census. It was selected in this study to evaluate the effects of anti-aging supplements. The selection criteria of the participants were that they had to be 20 years of age or older and to have given their written informed consent prior to participation. The exclusion criteria were as follows: pregnant women, women who were breast-feeding, and others judged as unfit to participate by a physician or study director. In total, the study included 124 participants (male=36, female=88, aged 22-86 years) who were enrolled in November 2013 (n=102) and in May $2014(n=22)$ (Figure 1).

This study was approved by the Institutional Review Board of Ehime University Hospital (authorization number 1309018). Written informed consent was obtained from all participants. 


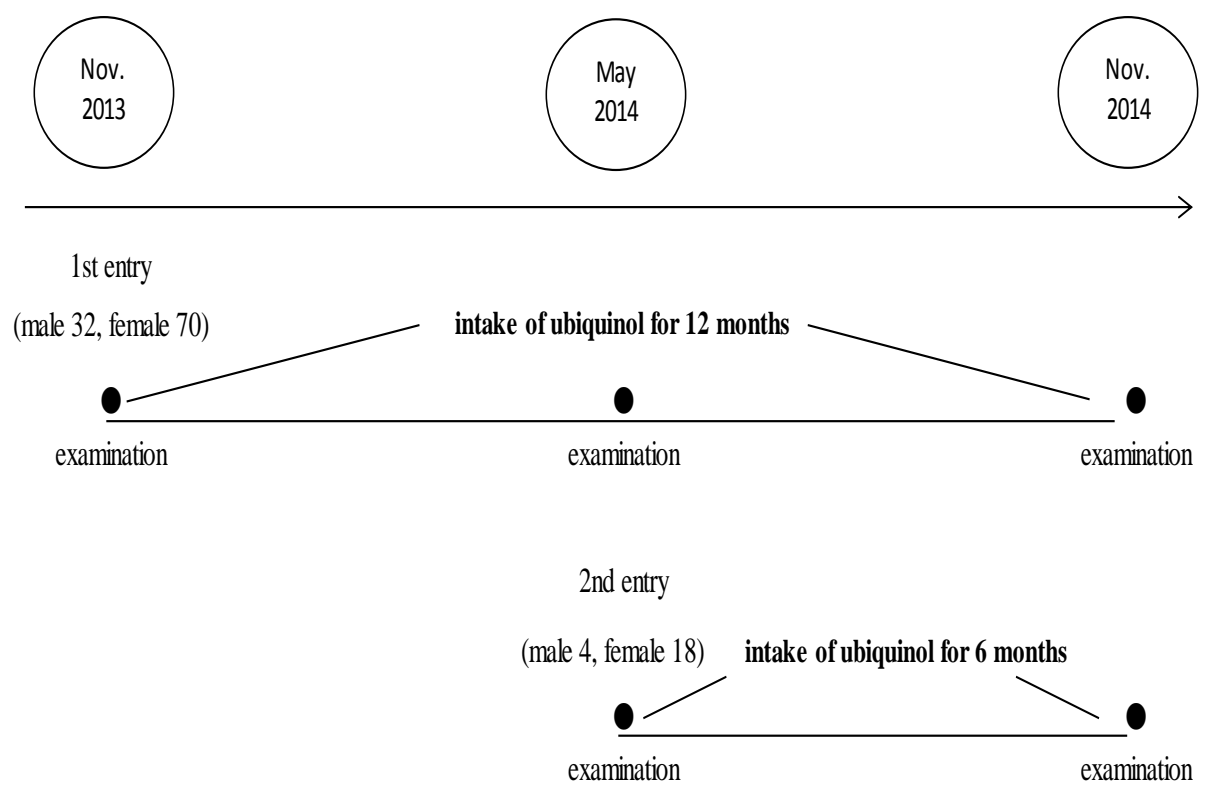

Figure 1. Outline of Ubiquinol Health Examination

\section{Study design}

We conducted this study by an open-label single-arm design. Participants consumed a supplement containing 100-120 mg of ubiquinol per day for either 6 or 12 months from the day they agreed to participate in the Ubiquinol Health Examination (Figure 1). Outcomes were measured at baseline and after the long-term intake of ubiquinol supplements. Since Ikematsu et al. reported that significant changes in plasma CoQ10 concentration had not been shown during 6 weeks in placebo intake group [24], we did not employ run-in period in this study. Participants were directed not to change their lifestyles during this trial. We confirmed that the lifestyle of participants had not changed substantially every 6 months using a questionnaire.

\section{Ubiquinol supplementation}

We prepared two types of ubiquinol supplements: granule and soft capsule, each of which contained 100-120 mg of ubiquinol (Kaneka Corporation, Osaka, Japan). Participants were given their preferred choice of format.

\section{Outcome measure}


We examined non-fasting blood tests, serum ubiquinol levels, plasma homocysteine, and serum pentosidine as markers of bone quality. Subjective QOL was measured by the Medical Outcome Study 36-Item Short-Form Health Survey (SF-36) [25-26]. SF-36 is a generic questionnaire that has been widely used to compare the impact of different medical conditions and as an outcome measure of different therapeutic interventions. The questionnaire is self-administered, and the participants were asked to complete 36 questions according to their experiences during the previous 4 weeks. The questions are divided into eight subscales and three dimensions that describe overall health status. The eight subscales are listed as follows: physical functioning (PF), role physical (RP), bodily pain (BP), general health (GH), vitality (VT), social functioning (SF), role emotional (RE), and mental health $(\mathrm{MH})$. The three dimensions are as follows: physical component summary (PCS), mental component summary (MCS), and role-social component summary (RCS), which are calculated from the scores of eight subscales by specific standardized algorithms [27]. Scores of each scale range from 0 to 100, with higher scores representing better QOL. We examined fatigue level, as the activation of mitochondrial energy production by ubiquinol would affect the fatigued states of participants [28]. Fatigue level was measured by stress level from the ratio of low frequency (LF) to high frequency (HF), the total power (TP) of autonomic function, and the coefficient of component variance total power (ccvtp). For examination, participants were asked to sit for two minutes at rest while holding a "Vital Monitor" device (Hitachi Systems, Ltd., Tokyo, Japan) in their hands.

\section{Statistical analysis}

We analyzed the changes in variables and correlations between the change in ubiquinol level and the changes in variables. For the analysis of changes, we used Wilcoxon signed-rank tests. For the analysis of correlation, we used Spearman's rank-correlation coefficient. We further analyzed the changes in SF-36 scores after stratifying the tertiles of baseline serum ubiquinol levels. Results with $\mathrm{P}<0.05$ in the two-sided tests were considered statistically significant. All statistical analyses were performed with SAS software (version 9.4; SAS Institute Inc., Cary, NC, USA

\section{RESULTS}

Table 1 shows the baseline characteristics of the participants. Serum ubiquinol levels were significantly higher in male participants than in females. With respect to SF-36 subscales, the scores of PF, RP, VT, and RE of males were significantly higher than those of females. Homocysteine of males was significantly higher than that of females. Other variables showed no 
significant differences between sexes.

Figure 2 shows the serum ubiquinol level of individuals at baseline and after the long-term intake of ubiquinol. Mean serum ubiquinol levels increased significantly after long-term intake (from 1.05 to $4.25 \mu \mathrm{g} / \mathrm{ml}, \mathrm{P}<0.01$ ). Table 2 shows the measurements at baseline and after long-term intake, as well as their changes for both male and female participants. In males, SF-36 scores did not show significant changes, while in females, the scores of RE, VT, SF, MH, and MCS increased significantly. Regarding fatigue level, significant improvement was not demonstrated in either sex. With respect to plasma homocysteine and serum pentosidine, no significant changes were found in males, while in females, plasma homocysteine increased significantly (from 9.4 to $9.6 \mathrm{nmol} / \mathrm{ml}, \mathrm{P}<0.01$ ).

Table 1 Baseline characteristics of participants

\begin{tabular}{|c|c|c|c|}
\hline & Male $(n=36)$ & Female $(n=88)$ & $\mathbf{P}$ \\
\hline Age & $58.1(16.2)$ & $59.8(14.9)$ & 0.9 \\
\hline BMI & $24.6(4.0)$ & $22.8(3.5)$ & $<0.01$ \\
\hline Hypertension (n, \%) & $13(35)$ & $22(25)$ & $0.25^{*}$ \\
\hline Hyperlipidemia (n, \%) & $11(30)$ & $19(22)$ & $0.33 *$ \\
\hline Diabetes $(\mathrm{n}, \%)$ & $4(11)$ & $4(5)$ & $0.23 *$ \\
\hline Smoking (n, \%) & $9(24)$ & $2(2)$ & $<0.01$ \\
\hline Ubiquinol ( $\mu \mathrm{g} / \mathrm{ml})$ & $1.15(0.34)$ & $1.00(0.55)$ & \multirow{2}{*}{$<0.01$} \\
\hline Ubiquinol $(\mu \mathrm{g} / \mathrm{ml}, \min -\max )$ & $0.63-1.85$ & $0.47-3.51$ & \\
\hline Ubiquinone $(\mu \mathrm{g} / \mathrm{ml})$ & $0.052(0.023)$ & $0.047(0.023)$ & 0.09 \\
\hline Total CoQ10 $(\mu \mathrm{g} / \mathrm{ml})$ & $1.20(0.36)$ & $1.05(0.57)$ & $<0.01$ \\
\hline Reduce form ratio (\%) & $95.6(1.24)$ & $95.4(1.26)$ & \multirow{2}{*}{0.16} \\
\hline Reduce form ratio (\%, min.-max) & $91.7-97.5$ & $89.9-97.4$ & \\
\hline \multicolumn{4}{|l|}{ SF-36 Scores } \\
\hline PF (Physical Functioning) & $52.7(9.0)$ & $48.8(12.0)$ & 0.03 \\
\hline RP (Role Physical) & $51.8(8.6)$ & $46.7(12.8)$ & 0.02 \\
\hline BP (Bodily Pain) & $52.1(9.9)$ & $50.3(9.2)$ & 0.30 \\
\hline GH (General Health) & $50.0(7.3)$ & $48.8(8.1)$ & 0.23 \\
\hline VT (Vitality) & $53.1(8.1)$ & $49.8(9.2)$ & 0.04 \\
\hline SF (Social Functioning) & $50.0(9.4)$ & $48.8(10.1)$ & 0.61 \\
\hline
\end{tabular}




\begin{tabular}{llll}
\hline & Male $(\mathbf{n}=\mathbf{3 6})$ & Female $(\mathbf{n = 8 8})$ & P \\
\hline RE (Role Emotional) & $52.2(8.6)$ & $47.5(12.0)$ & 0.02 \\
MH (Mental Health) & $51.0(7.0)$ & $49.8(9.3)$ & 0.60 \\
PCS (Physical Component Summary ) & $51.7(8.3)$ & $48.5(12.0)$ & 0.27 \\
MCS (Mental Component Summary ) & $51.4(8.2)$ & $51.3(9.9)$ & 0.82 \\
RCS (Role-Social Component Summary ) & $50.4(9.3)$ & $46.8(14.2)$ & 0.21 \\
Fatigue degree & & & \\
LF/HF & $3.48(7.27)$ & $2.07(1.83)$ & 0.25 \\
TP (msec2) & $672(867)$ & $574(888)$ & 0.13 \\
$\quad$ ccvTP $(\%)$ & $2.60(1.7)$ & $2.28(1.40)$ & 0.26 \\
Homocysteine $(\mathrm{nmol} / \mathrm{ml})$ & $12.3(4.7)$ & $9.4(3.3)$ & $<0.01$ \\
Pentosidine $(\mu \mathrm{g} / \mathrm{ml})$ & $0.042(0.017)$ & $0.040(0.013)$ & 0.91 \\
\hline
\end{tabular}

Values are expressed as mean \pm standard deviation.

* chi-squared test and other indices are analyzed by the Wilcoxon rank-sum test.

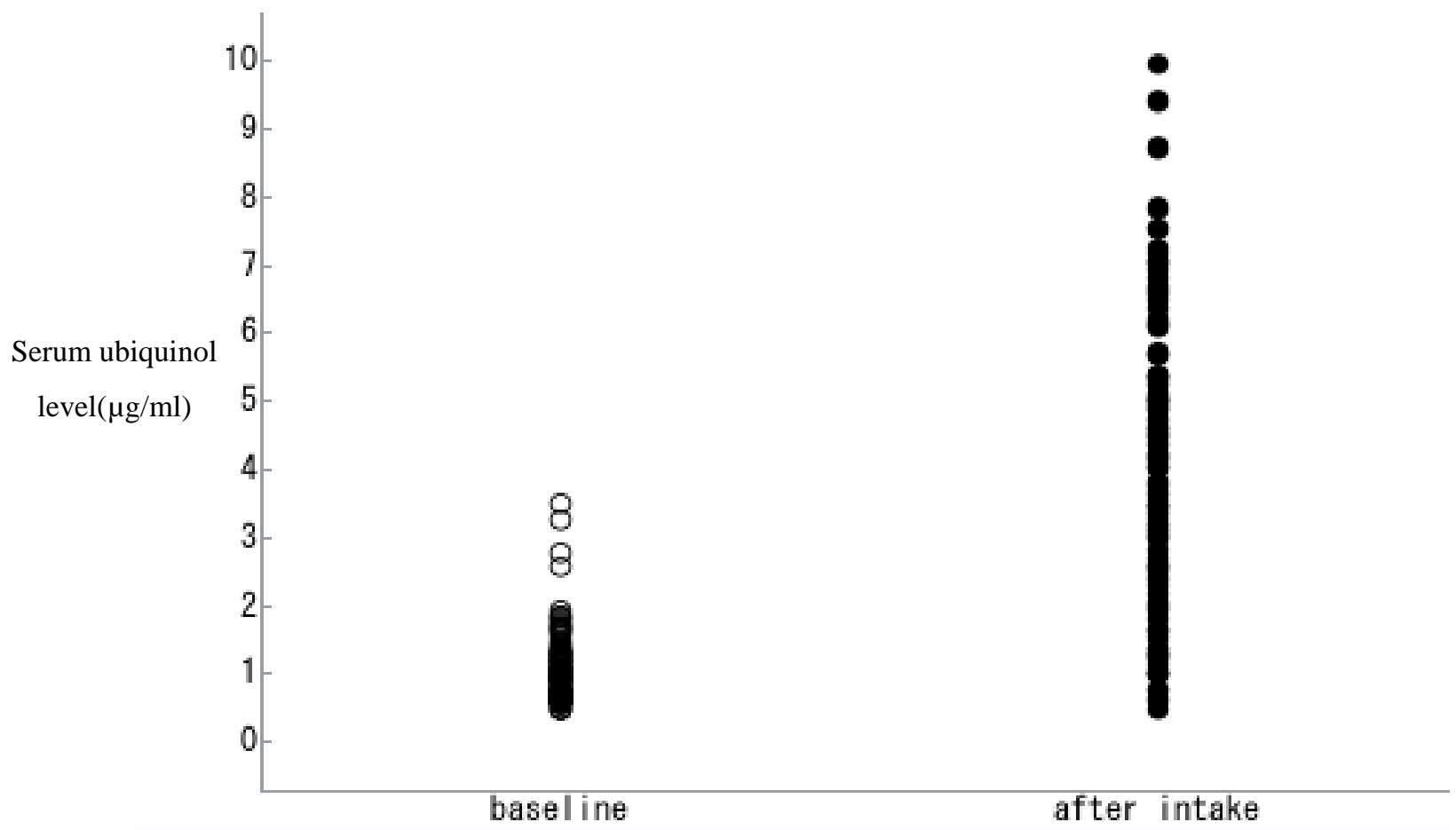

Figure 2. Serum ubiquinol levels at baseline and after long-term intake

Baseline serum ubiquinol levels are indicated by white circles, those after intake are indicated by black circles 
Table 2 Measurements at baseline and after long-term intake, and the changes in variables.

\begin{tabular}{|c|c|c|c|c|c|c|c|c|}
\hline & \multicolumn{4}{|c|}{ male $(n=36)$} & \multicolumn{4}{|c|}{ female $(n=88)$} \\
\hline & baseline & $\begin{array}{c}\text { after 6-12 } \\
\text { months }\end{array}$ & $\Delta$ & $\mathrm{P}$ & baseline & $\begin{array}{l}\text { after 6-12 } \\
\text { months }\end{array}$ & $\Delta$ & $\mathrm{P}$ \\
\hline Ubiquinol ( $\mu \mathrm{g} / \mathrm{ml})$ & $1.15(0.34)$ & $3.99(2.68)$ & $2.84(2.54)$ & $<0.01$ & $1.00(0.53)$ & $4.32(2.23)$ & $3.32(2.26)$ & $<0.01$ \\
\hline Ubiquinone $(\mu \mathrm{g} / \mathrm{ml})$ & $0.052(0.023)$ & $0.34(0.22)$ & $0.29(0.22)$ & $<0.01$ & $0.047(0.025)$ & $0.27(0.19)$ & $0.23(0.19)$ & $<0.01$ \\
\hline Total CoQ10 $(\mu \mathrm{g} / \mathrm{ml})$ & $1.20(0.36)$ & $4.34(2.74)$ & $3.13(2.59)$ & $<0.01$ & $1.05(0.57)$ & $4.59(2.34)$ & $3.55(2.37)$ & $<0.01$ \\
\hline Reduce form ratio (\%) & $95.6(1.2)$ & $90.6(7.2)$ & $-5.0(7.4)$ & $<0.01$ & $95.4(1.3)$ & $93.6(3.9)$ & $-1.8(4.1)$ & $<0.01$ \\
\hline \multicolumn{9}{|l|}{ SF-36 Scores } \\
\hline $\mathrm{PF}$ & $52.7(9.0)$ & $51.9(8.7)$ & $-1.0(3.7)$ & 0.15 & $48.8(12.0)$ & $48.4(12.2)$ & $-0.37(8.9)$ & 0.83 \\
\hline $\mathrm{RP}$ & $51.8(8.6)$ & $49.0(10.4)$ & $-2.9(9.7)$ & 0.11 & $46.7(12.8)$ & $49.8(8.8)$ & $3.1(12.6)$ & 0.04 \\
\hline $\mathrm{BP}$ & $52.1(9.9)$ & $50.2(10.1)$ & $-2.2(10.4)$ & 0.33 & $50.3(9.2)$ & $49.6(8.5)$ & $-0.74(9.9)$ & 0.40 \\
\hline $\mathrm{GH}$ & $50.0(7.3)$ & $49.5(7.7)$ & $-0.20(7.1)$ & 0.87 & $48.8(8.1)$ & $49.4(7.5)$ & $0.61(6.7)$ & 0.18 \\
\hline VT & $53.1(8.1)$ & $52.5(7.3)$ & $-0.37(7.1)$ & 0.60 & $49.8(9.2)$ & $52.8(8.1)$ & $3.0(8.3)$ & $<0.01$ \\
\hline SF & $50.0(9.4)$ & $51.6(8.7)$ & $2.2(7.7)$ & 0.13 & $48.8(10.1)$ & $52.0(8.3)$ & $3.2(10.6)$ & $<0.01$ \\
\hline $\mathrm{RE}$ & $52.2(8.6)$ & $50.5(9.1)$ & $-1.7(8.8)$ & 0.24 & $47.5(12.0)$ & $49.8(8.8)$ & $2.4(11.0)$ & 0.09 \\
\hline MH & $51.0(7.0)$ & $49.5(7.3)$ & $-1.2(8.0)$ & 0.40 & $49.8(9.3)$ & $52.1(8.2)$ & $2.3(8.5)$ & 0.02 \\
\hline PCS & $51.7(8.3)$ & $50.0(9.6)$ & $-2.3(6.6)$ & 0.09 & $48.5(12.0)$ & $46.5(11.5)$ & $-2.0(9.9)$ & 0.14 \\
\hline MCS & $51.4(8.2)$ & $51.1(7.6)$ & $0.29(7.1)$ & 0.77 & $51.3(9.9)$ & $53.0(8.1)$ & $1.7(7.9)$ & 0.03 \\
\hline RCS & $50.4(9.3)$ & $49.8(9.2)$ & $-0.45(9.3)$ & 0.90 & $46.8(14.2)$ & $50.8(8.3)$ & $4.0(14.9)$ & 0.11 \\
\hline \multicolumn{9}{|l|}{ Fatigue degree } \\
\hline $\mathrm{LF} / \mathrm{HF}$ & $3.48(7.27)$ & $3.62(6.85)$ & $0.23(9.24)$ & 0.53 & $2.07(1.83)$ & $2.08(2.05)$ & $0.025(2.44)$ & 0.77 \\
\hline $\mathrm{TP}(\mathrm{msec} 2)$ & $672(870)$ & $422(437)$ & $-246(804)$ & $<0.01$ & $574(888)$ & $476(697)$ & $-101(684)$ & 0.18 \\
\hline $\operatorname{ccvTP}(\%)$ & $2.60(1.69)$ & $2.13(1.19)$ & $-0.48(1.38)$ & 0.02 & $2.28(1.40)$ & $2.18(1.37)$ & $-0.12(1.19)$ & 0.31 \\
\hline Homosysteine (nmol/ml) & $12.3(4.7)$ & $12.4(4.7)$ & $0.17(2.4)$ & 0.75 & $9.4(3.3)$ & $9.6(2.5)$ & $0.23(2.0)$ & $<0.01$ \\
\hline Pentosidine $(\mu \mathrm{g} / \mathrm{ml})$ & $0.042(0.017)$ & $0.044(0.018)$ & $0.002(0.02)$ & 0.63 & $0.040(0.013)$ & $0.043(0.018)$ & $0.002(0.02)$ & 0.43 \\
\hline
\end{tabular}

Values are expressed as mean \pm standard deviation.

Wilcoxon signed-rank test. 
Table 3 shows the correlation coefficients between the change in serum ubiquinol level and the change in SF-36 scores. In both sexes, significant correlations were not found.

Table 4 shows the changes in SF-36 scores after stratifying baseline serum ubiquinol levels by tertile. In the low ubiquinol level group of female participants, the scores of VT and MCS improved significantly, whereas the scores of PF and MCS decreased significantly. In the middle ubiquinol level group of female participants, the scores of PF, RP, VT, SF, and MH improved significantly. Meanwhile in males, SF-36 scores did not show significant changes in any tertile.

Table 3 Correlations between the change in serum ubiquinol level and the change in SF-36 scores.

\begin{tabular}{lccc}
\hline & Male $(\mathrm{n}=36)$ & Female $(\mathrm{n}=88)$ & Total $(\mathrm{n}=124)$ \\
\hline PF & $\mathrm{r}=0.06$ & $\mathrm{r}=-0.11$ & $\mathrm{r}=-0.05$ \\
& $\mathrm{P}=0.71$ & $\mathrm{P}=0.3$ & $\mathrm{P}=0.59$ \\
RP & 0.01 & -0.03 & -0.08 \\
& 0.94 & 0.79 & 0.36 \\
BP & 0.08 & 0.07 & 0.07 \\
& 0.63 & 0.50 & 0.47 \\
GH & -0.13 & -0.17 & -0.16 \\
& 0.45 & 0.12 & 0.09 \\
VT & 0.12 & -0.03 & 0.04 \\
& 0.50 & 0.77 & 0.69 \\
SF & -0.08 & 0.07 & 0.009 \\
& 0.66 & 0.50 & 0.92 \\
RE & 0.25 & 0.00006 & 0.04 \\
& 0.16 & 1.00 & 0.66 \\
MH & 0.13 & 0.05 & 0.02 \\
& 0.44 & 0.68 & 0.81 \\
PCS & -0.11 & -0.14 & 0.02 \\
& 0.52 & 0.19 & 0.81 \\
MCS & -0.003 & 0.03 & 0.02 \\
RCS & 0.99 & 0.80 & 0.81 \\
& 0.08 & 0.09 & 0.02 \\
\hline & 0.62 & 0.42 & 0.81 \\
\hline
\end{tabular}


Spearman's rank-correlation analysis.

Above line indicates correlation coefficients (r), below line indicates P-value.

Table 4 Changes in QOL scores after stratifying baseline serum ubiquinol levels by tertiles.

Male (n=36)

\begin{tabular}{|c|c|c|c|c|c|c|}
\hline & \multicolumn{6}{|c|}{ Baseline serum ubiquinol levels $(\mu \mathrm{g} / \mathrm{ml})$} \\
\hline & \multirow{2}{*}{\multicolumn{2}{|c|}{$\begin{array}{c}\text { Low }(\mathrm{n}=12) \\
0.80 【 0.65-0.96 】\end{array}$}} & \multirow{2}{*}{\multicolumn{2}{|c|}{$\begin{array}{c}\text { Middle }(\mathrm{n}=12) \\
1.16 【 0.99-1.26 】\end{array}$}} & \multirow{2}{*}{\multicolumn{2}{|c|}{$\begin{array}{c}\text { High }(\mathrm{n}=12) \\
1.54 【 1.27-1.84 】\end{array}$}} \\
\hline & & & & & & \\
\hline & change & $\mathrm{P}$ value & change & $\mathrm{P}$ value & change & $\mathrm{P}$ value \\
\hline PF & -2.3 & 0.17 & -0.75 & 0.53 & 0 & 1.00 \\
\hline $\mathrm{RP}$ & -3.7 & 0.06 & -2.0 & 0.88 & -3.1 & 0.44 \\
\hline BP & -2.2 & 0.31 & -6.6 & 0.09 & 2.3 & 0.38 \\
\hline GH & -1.7 & 0.45 & 1.4 & 0.67 & -0.27 & 0.74 \\
\hline VT & 1.7 & 0.64 & -2.1 & 0.38 & -0.77 & 0.51 \\
\hline SF & 4.4 & 0.09 & 0 & 1.00 & 2.2 & 0.50 \\
\hline $\mathrm{RE}$ & -6.0 & 0.06 & 0.35 & 0.95 & 0.71 & 1.00 \\
\hline MH & -0.44 & 0.69 & -2.0 & 0.43 & -1.1 & 0.88 \\
\hline PCS & -4.4 & 0.08 & -2.2 & 0.47 & -0.23 & 0.97 \\
\hline MCS & 2.4 & 0.30 & -1.8 & 0.79 & 0.25 & 0.91 \\
\hline $\mathrm{RCS}$ & -1.7 & 0.85 & 0.51 & 0.79 & -0.16 & 0.52 \\
\hline
\end{tabular}

Female $(n=88)$

\begin{tabular}{|c|c|c|c|c|c|c|}
\hline & \multicolumn{6}{|c|}{ Baseline serum ubiquinol levels $(\mu \mathrm{g} / \mathrm{ml})$} \\
\hline & \multirow{2}{*}{\multicolumn{2}{|c|}{$\begin{array}{c}\text { Low }(n=29) \\
0.60 【 0.47-0.70 】\end{array}$}} & \multirow{2}{*}{\multicolumn{2}{|c|}{$\begin{array}{c}\text { Middle }(\mathrm{n}=30) \\
0.86 【 0.72-1.02 】\end{array}$}} & \multirow{2}{*}{\multicolumn{2}{|c|}{$\begin{array}{c}\text { High }(\mathrm{n}=29) \\
1.54 【 1.02-3.51 】\end{array}$}} \\
\hline & & & & & & \\
\hline & change & $\mathrm{P}$ value & change & $\mathrm{P}$ value & change & $\mathrm{P}$ value \\
\hline $\mathrm{PF}$ & -4.3 & 0.04 & 2.1 & 0.03 & 1.0 & 0.87 \\
\hline $\mathrm{RP}$ & 0.94 & 0.90 & 7.4 & $<0.01$ & 0.71 & 0.50 \\
\hline BP & -1.6 & 0.29 & -1.5 & 0.65 & 0.87 & 1.00 \\
\hline GH & 0.48 & 0.46 & 0.036 & 0.60 & 1.3 & 0.098 \\
\hline VT & 3.4 & $<0.01$ & 4.6 & 0.045 & 1.0 & 0.48 \\
\hline SF & 2.7 & 0.098 & 5.3 & 0.03 & 1.6 & 0.37 \\
\hline $\mathrm{RE}$ & 1.2 & 0.77 & 4.7 & 0.13 & 1.2 & 0.20 \\
\hline MH & 1.5 & 0.31 & 4.4 & 0.03 & 1.0 & 0.57 \\
\hline PCS & -5.0 & 0.03 & -1.6 & 0.61 & 0.61 & 0.97 \\
\hline MCS & 2.9 & 0.04 & 1.2 & 0.49 & 1.0 & 0.34 \\
\hline $\mathrm{RCS}$ & 2.8 & 0.63 & 8.1 & 0.098 & 0.84 & 0.51 \\
\hline
\end{tabular}

Values are expressed as mean \pm standard deviation. Baseline serum ubiquinol levels of each tertile are indicated by average and [min-max], respectively. Wilcoxon signed-rank test (the changes from baseline to after 6-12 months.

\section{DISCUSSION}

The main finding of this study was the effect of ubiquinol on female participants' QOL 
improvement, especially their psychological QOL. To evaluate the psychological QOL, the questionnaires relating to vitality and mental condition were used, for instance "Did you feel full of pep?" "Have you been a very nervous person?"

Ubiquinol is known to play a key role in mitochondrial energy production [2], and administering ubiquinol has previously been tested as a way to enhance vitality or reduce fatigue in hospital-based studies [15-17, 29-30]. In addition, SF-36 scores have shown a significance or tendency for improvement in the clinical trials of L-carnitine [31-32], which is considered to function in the tricarboxylic acid cycle as a producer of mitochondrial energy like ubiquinol [33-34]. Another well-known key role of ubiquinol is its antioxidant effect [4-5]. In this study, we observed significant increment of serum ubquinol levels after long term intervention. A review [2] indicated that since a majority of the coenzyme $Q$ in cell membranes was in the quinol form, it could be a very effective antioxidant. The absolute amount of ubiquinol level in serum could reflect the amount of the coenzyme $\mathrm{Q}$ in cell membranes Therefore, we thought that the increment of serum ubiquinol levels may surrogate well antioxidant effects for our subjects. A previous study using animals reported that dietary supplementation with CoQ10 reduced brain oxidative stress and improved the psychological condition of the test subjects [35]. It was suggested that ubiquinol activates the mitochondrial energy production cycle and antioxidant effects, leading to improvement in the QOL of females.

Contrary to previous studies such as the trials for CHF [23, 35-37], chronic fatigue syndrome [28], and Parkinson's disease [13, 38], in the present study, the participants were primarily a healthy population. Therefore, mean levels of serum ubiquinol in the present participants would typically be higher than those of less healthy patients. It should be noted that the daily dose tested in the present study was administered at the same level as commonly-used in over-the-counter doses (100-120 mg/day), since the participants were healthy overall. In hospital-based studies, significantly high doses (1200-2400 mg/day) of CoQ10 have been administered $[28,38]$. In the present study using healthy residents, we were able to demonstrate the effects of commonly-used dosages of ubiquinol intake on females' QOL, especially for those whose serum ubiquinol levels were at a lower or middle range.

Regarding the lack of significant improvement in the QOL of male participants, we suggest a few possible reasons. First, males had high baseline scores of SF-36 compared to females to begin with. Even in females, significant improvements of QOL scores were not seen in the highest baseline tertile. In male participants, though 10 of 11 SF-36 scores for males trended lower, every subscale score after ubiquinol intake indicated around 50, those were standard 
levels. We consider that those were non-substantial changes within normal ranges. Second, males had higher baseline serum ubiquinol levels than females. This is probably due to the amount amount of daily foods sources for coenzyme Q10 intakes, i.e. meats and fishes. Therefore, the increment of ubiquinol levels could not contribute on male's QOL. Additionally, it is quite possible that in males, QOL scores were more affected by residual confounding factors, which were not examined in this study, rather than by serum ubiquinol levels.

Significant correlations between a change in serum ubiquinol level and a change in SF-36 scores were not shown in either sex. While the serum ubiquinol level increased significantly, and several of the SF-36 scores improved significantly in female participants, no significant correlation was observed between the change in ubiquinol level and the changes in SF-36 scores. However, this does not mean that the more serum ubiquinol levels increase, the more QOL scores improve. It is possible that serum ubiquinol levels have an optimal threshold, after which point any increase in the level would not lead to further improvement in QOL.

With respect to fatigue level, we failed to demonstrate a significant improvement, although we had an a priori hypothesis that activating energy production by ubiquinol should affect autonomic TP. These results could be due to the strong correlation between TP and aging (internal data). Since this study was a long-term trial, it is suggested that the effects of aging were stronger than the effects of ubiquinol intake.

During this long-term trial, we saw no serious side effects caused by ubiquinol. As shown in Table 2, homocysteine increased significantly in females (from 9.4 to $9.6 \mathrm{nmol} / \mathrm{ml}$ ). However, this increase was within normal range and could even be due to advancing age, given the fairly long intake periods of this study. In any case, continued follow-up is needed throughout this ongoing trial.

One of the strengths of our study is that it is the first large-scale and long-term trial among community residents to evaluate the effects of ubiquinol on QOL improvement. Most previous studies on CoQ10 have evaluated its effects on patients with pre-existing illnesses. We also showed the effects of ubiquinol on the QOL improvement of female participants with relatively low serum ubiquinol levels.

With regard to limitations, we first acknowledge that since this study was an open-labeled and single-arm trial, the findings might have included some placebo or period effects. However, the improvements of QOL were found only in female participants and mainly in the mental status scores. If the placebo or period effects were strong, the improvement should have been found in male participants as well as in the physical status scores. Second, we found effects only on 
subjective QOL, and not on objective variables such as fatigue level and blood examination. However, SF-36 has already been validated and used in many studies, even though it is a subjective questionnaire. For instance, the antioxidant effect of ubiquinol is known to complement the antioxidant activity of Vitamin E [39-40], and in the clinical trials of Vitamin E supplementation, SF-36 subscales have been used for evaluation [41-42].

With the population aging rapidly, many developed countries are now facing social problems related to their health insurance systems and medical costs. In these circumstances, the general public and communities are required to take charge of their own healthcare activities as a way of reducing medical spending, especially in terms of their healthy life-span. Clinical trials among healthy populations, such as the study reported here, will increase in importance in the years to come as new strategies for the prevention of diseases.

\section{CONCLUSIONS}

In our study, we discovered evidence demonstrating significant effects of ubiquinol on the mental condition of female participants. We will continue the follow-up with the test population, with the enrollment of additional participants and investigation of other anticipated effects of ubiquinol, including the functioning of mitochondrial energy production and antioxidant activity.

Abbreviations: QOL, quality of life; CoQ10, coenzyme Q10; NADPH, nicotinamide adenine dinucleotide phosphate; SF-36, Medical Outcome Study 36-Item Short-Form Health Survey; PF, physical functioning; RP, role physical; BP, bodily pain; GH, general health; VT, vitality; SF, social functioning; RE, role emotional; $\mathrm{MH}$, mental health; PCS, physical component score; MCS, mental component score; RCS, role-social component score; LF, low frequency; HF, high frequency; TP, total power; ccvtp, coefficient of component variance total power

Competing Interests: This study was supported by funding from the Kaneka Corporation (Osaka, Japan) based on the contract agreement between Kaneka and the Institute of Community Life Sciences Co., Ltd. Tetsu Kinoshita is a manager of this company. Kaneka had no commitment in the data analysis and interpretation. Takeshi Tanigawa and Koutatsu Maruyama had no personal or financial conflict of interest.

Author's contributions: All authors contributed to this study. 
Acknowledgements and funding: We thank the staff of Non-Profit Organization Shima-no-daigaku and Dr. Shinsuke Hata for their valuable contributions. This study was supported by funding from the Kaneka Corporation (Osaka, Japan) based on the contract agreement between Kaneka and the Institute of Community Life Sciences Co., Ltd.

\section{REFERENCES}

1. Department of economic and social affairs population division. World Population Ageing: 1950-2050. New York: United Nations, 2011.

2. Crane FL: Biochemical functions of coenzyme Q10. J Am Coll Nutr 2001, 20(6): 591-598.

3. Redfearn ER, Pumphrey AM: Oxidation-reduction levels of ubiquinone (coenzyme Q) in different metabolic states of rat liver mitochondria. Biochem Biophys Res Commun 1960, 3: $650-653$.

4. Stocker R, Bowry VW, Frei B: Ubiquinol-10 protects human low density lipoprotein more efficiently against lipid peroxidation than does $\alpha$-tocopherol. Proc Natl Acad Sci 1991, 88: 1646-1650.

5. Bowry VW, Stanley KK, Stocker R: High density lipoprotein is the major carrier of lipid hydroperoxides in human blood plasma from fasting donors. Proc Natl Acad Sci 1992, 89: 10316-10320.

6. Block G, Jensen CD, Norkus EP, et al: Usage patterns, health, and nutritional status of long-term multiple dietary supplement users: a cross-sectional study. Nutrition Journal 2007, 6: 30 .

7. Folkers K, Vadhanavikit S, Mortensen SA: Biochemical rationale and myocardial tissue data on the effective therapy of cardiomyopathy with coenzyme Q10. Proc Natl Acad Sci 1992, 89: 10316-10320.

8. Onur S, Niklowits P, Jacobs G, Lieb W, Menke T, Doring F: Association between serum level of ubiquinol and NT-proBNP, a marker for chronic heart failure, in healthy elderly subjects. BioFactors 2015, 41: 35-43.

9. Madmani ME, Yusef SA, Tamr AK, Madmani Y, Shahrour Y, Essali A, Kadro W: Coenzyme Q10 for heart failure (Review). The Cochrane Collaboration 2014, 6.

10. Morris G, Anderson G, Berk M, Maes M: Coenzyme Q10 depletion in medical and neuropsychiatric disorders: Potential repercussions and therapeutic implications. Mol Neurobiol 2013, 48: 883-903.

11. Filler K, Lyon D, Bennett J, McCain N, Elswick R, Lukkahatai N, Saligan LN: Association 
of mitochondrial dysfunction and fatigue: A review of the literature. BBA Clin 2014, 1: $12-23$.

12. Mezawa M, Takemoto M, Onishi S, Ishibashi R, Ishikawa T, Yamaga M, Fujimoto M, Okabe E, He P, Kobayashi K, Yokote K: The reduced form of coenzyme Q10 improves glycemic control in patients with type 2 diabetes: An open label pilot study. BioFactors. 2012, 38: 416-421.

13. Shults CW, Oakes D, Kieburtz K, Beal MF, Haas R, Plumb S, Juncos JL, Nutt J, Shoulson I, Carter J, Kompoliti K, Perlmutter JS, Reich S, Stern M, Watts RL, Kurlan R, Molho E, Harrison M, Lew M: Effects of coenzyme Q10 in early Parkinson Disease: Evidence of slowing of the functional decline. Arch Neurol 2002, 59: 1541-1550.

14. Yamagishi K, Ikeda A, Moriyama Y, Chei CL, Noda H, Umesawa M, Cui R, Nagao M, Kitamura K, Yamamoto Y, Asada T, Iso H: Serum coenzyme Q10 and risk of disabling dementia: the Circulatory Risk in Communities Study (CIRCS). Atherosclerosis 2014, 237: 400-403.

15. Hofman-Bang C, Rehnqvist N, Swedberg K, Wiklund I, Astrom H: Coenzyme Q10 as an adjunctive in the treatment of chronic congestive heart failure. The Q10 Study Group. J Card Fail 1995, 1: 101-107.

16. Lister R: An open, pilot study to evaluate the potential benefits of coenzyme Q10 combined with Ginkgo Biloba extract in Fibromyalgia Syndrome. J Int Med Res 2002, 30: 195-199.

17. Witte KK, Nikitin NP, Parker AC, Haehling S, Volk HD, Anker SD, Clark AL, Cleland JGF: The effect of micronutrient supplementation on quality-of-life and left ventricular function in elderly patients with chronic heart failure. Eur Heart J 2005, 26: 2238-2244.

18. World Health Organization. Constitution in basic documents. Geneva: World Health Organization; 1948.

19. Spilker B: Quality of life and pharmacoeconomics in clinical trials. Philadelphia $\cdot$ New York :Lippincott Williams \& Wilkins, 1996, 1-10.

20. Deguchi S, Fujii K, Kurihara T: The effect of the reduced form of coenzyme Q10 (ubiquinol, Kaneka QHTM) on QOL improvement in the elderly. Journal of Clinical Therapeutics \& Medicines 2008, 24: 233-238.

21. Aberg F, Appelkvist EL, Dallner G, Ernster L: Distribution and redox state of ubiquinones in rat and human tissues. Arch Biochem Biophys 1992, 295: 230-234.

22. Langsjoen PH, Langsjoen AM: Supplemental ubiquinol in patients with advanced congestive heart failure. BioFactors 2008, 32: 119-128. 
23. Yan J, Fujii K, Yao J, Higuchi K: Reduced coenzyme Q10 supplementation decelerates senescence in SAMP1 mice. Exp Gerontol 2006, 41: 130-140.

24. Ikematsu H, Nakamura K, Harashima S, Fujii K, Fukutomi N: Safety assessment of coenzyme Q10 (Kaneka Q10) in healthy subjects: A double-blind, randomized, placebo-controlled trial. Regul Toxicol Pharmacol 2006, 44: 212-218.

25. Fukuhara S, Bito S, Green J, Hsiao A, Kurokawa K: Translation, adaptation, and validation of the SF-36 Health Survey for use in Japan. J Clin Epidemiol 1998, 51: 1037-1044.

26. Fukuhara S, Ware J E, Kosinski M, Wada S, Gandek B: Psychometric and clinical tests of validity of the Japanese SF-36 Health Survey. J Clin Epidemiol 1998, 51: 1045-1053.

27. Fukuhara S, Suzukamo Y: Manual of SF-36 v2, Japanese version. Kyoto: Institute for Health Outcomes \& Process Evaluation Research, 2004.

28. Castro-Marrero J, Codero MD, Segundo MJ, Saez-Francas N, Calvo N, Roman-Malo L, Aliste L, Sevilla TF, Alegre1 J: Does oral coenzyme Q10 plus NADH supplementation improve fatigue and biochemical parameters in chronic fatigue syndrome? Antioxidant \& Redox Signaling 2015, 22: 679-685.

29. Glover EI, Martin J, Maher A, Thornhill RE, Moran GR, Tarnopolsky MA: A randomized trial of coenzyme Q10 in mitochondrial disorders. Muscle Nerve 2010, 42:739-748.

30. Fukuda S, Koyama H, Kondo K, Fujii H, Hirayama Y, Tabata T, Okamura M, Yamakawa T, Okada S, Hirata S, Kiyama H, Kajimoto O, Watanabe Y, Inaba M, Nishizawa Y: Effects of nutritional supplementation on fatigue, and autonomic and immune dysfunction in patients with end-stage renal disease: A randomized, double-blind, placebo-controlled, multicenter trial. PLOS ONE 2015, 10(3): e0119578.

31. Steiber AL, Davis AT, Spry L, Strong J, Buss ML, Ratkiewicz MM, Weatherspoon LJ: Carnitine treatment improved quality-of-life measure in a sample of Midwestern hemodialysis patients. JPEN J Parenter Enteral Nutr 2006, 30: 10-15.

32. Miyagawa T, Kawamura H, Obuchi M, Ikesaki A, Ozaki A, Tokunaga K, Inoue Y, Honda M: Effects of oral L-carnitine administration in narcolepsy patients: A randomized, double-blind, cross-over, and placebo-controlled trial. PLOS ONE 2013, 8(1): e53707.

33. Bertelli A, Bertelli AA, Giovannini L, Spaggiari P: Protective synergic effect of coenzyme Q10 and carnitine on hyperbaric oxygen toxicity. Int J Tissue React 1990, 12: 193-196.

34. Conte A, Palmieri L, Ronca G, Giovannini L, Bertelli A: Synergic and complementary effects of L-carnitine and coenzyme Q10 on long-chain fatty acid metabolism and on protection against anthracycline damage. Int J Tissue React 1990, 12: 197-201. 
35. Sander S, Coleman CI, Patel AA, Kluger J, White CM: The impact of coenzyme Q10 on systolic function in patients with chronic heart failure. J Card Fail 2006, 12: 464-472.

36. Mortensen SA, Rosenfeldt F, Kumar A, Dolliner P, Filipiak KJ, Pella D, Alehagen U, Steurer G, Littarru GP: The effects of coenzyme Q10 on morbidity and mortality in chronic heart failure. Results from Q-SYMBIO: A randomized double-blind trial. Heart Failure 2014, 2: 641-649.

37. Fotino AD, Thompson-Paul M, Bazzano LA: Effect of coenzyme Q10 supplementation on heart failure: a meta-analysis. Am J Clin Nutr 2013, 97: 268-275.

38. Parkinson Study Group QE3 Investigators, Beal MF, Oakes D, Shoulson I, Henchcliffe C, et al.: A randomized clinical trial of high-dosage coenzyme Q10 in early Parkinson disease. JAMA Neurol 2014, 71: 543-552.

39. Yamamoto Y, Komuro E, Niki E: Antioxidant activity of ubiquinol in solution and phosphatidylcholine liposome. J Nutr Sci Vitaminol 1990, 36: 505-511.

40. Thomas SR, Leichtweis SB, Pettersson K, Croft KD, Mori TA, Brown AJ, Stocker R: Dietary cosupplementation with Vitamin E and coenzymeQ10 inhibits atherosclerosis in apolipoprotein E gene knockout mice. Arterioscler Thromb Vasc Biol 2001, 21: 585-593.

41. Biglia N, Sgandurra P, Peano E, Marenco D, Moggio G, Bounous V, Tomasi Cont N, Ponzone R, Sismondi P: Non-hormonal treatment of hot flushes in breast cancer survivors: gabapentin vs. vitamin E. Climacteric 2009, 12: 310-318.

42. Kirk GR, White JS, McKie L, Stevenson M, Young I, Clements WD, Rowlands BJ: Combined antioxidant therapy reduces pain and improves quality of life in chronic pancreatitis. J Gastrointest Surg 2006, 10: 499-503. 